\title{
Redox regulation of protein kinase $\mathbf{G}$ Philip Eaton
}

\author{
Address: Cardiovascular Division, King's College London, UK \\ Email: Philip Eaton - philip.eaton@kcl.ac.uk
}

from 4th International Conference of cGMP Generators, Effectors and Therapeutic Implications

Regensburg, Germany. 19-21 June 2009

Published: II August 2009

BMC Pharmacology 2009, 9(Suppl I):SI0 doi:10.1186/I47I-22I0-9-SI-SI0

This abstract is available from: http://www.biomedcentral.com//47I-22I0/9/SI/SI0

(c) 2009 Eaton; licensee BioMed Central Ltd.

Oxidants were once primarily considered in biology and medicine in terms of the injury they might cause. However, oxidants are now known to play crucial roles in homeostatic control of cells and tissues during health. Oxidative modification of proteins with a coupled alteration in function allows cells to sense and transduce these 'oxidant signals' into a biological response. We looked for proteins with redox sensitive cysteine thiols that detect (by becoming modified by) cellular oxidants. Proteomic studies eventually lead to the identification of protein kinase G (specifically the I $\alpha$ isoform) as an oxidant sensor and signal transducer. This kinase is fundamentally important in the regulation of blood pressure and other important processes in the cardiovascular system. PKG is classically activated by the nitric oxide/cGMP pathway. Oxidative stress causes interprotein disulfide formation between adjacent Cys-42 residues in the PKGI $\alpha$ homodimer complex. Disulfide oxidation renders the kinase catalytically active without the need for cGMP. This oxidative activation is mediated by the disulfide state having a 7-fold increased affinity for substrate, which contrasts CGMP activation which elevates the enzymes Vmax. Consistent with disulfide-mediated activation of PKGIa hydrogen peroxide induces vasorelaxation in isolated hearts and aortic rings. Hydrogen peroxide-induced vasorelaxation is PKG-dependent (blocked by KT5823), but again cGMP-independent (not blocked by ODQ). Disulfide activation of PKG1 $\alpha$ in smooth muscle cells induces co-association with, and phosphorylation of, substrate proteins that coordinate vasotone. These events were absent in cells expressing 'redox-dead' Cys42Ser PKG1 $\alpha$, which cannot form a disulfide during oxidative interventions. This novel mode oxidation-induced activa- tion represents a novel paradigm in PKG biology, in which kinase oxidation bypasses classical activation by the nitric oxide pathway. These observations provide a molecular explanation for how hydrogen peroxide can operate as an endothelium-derived hyperpolarizing factor. 